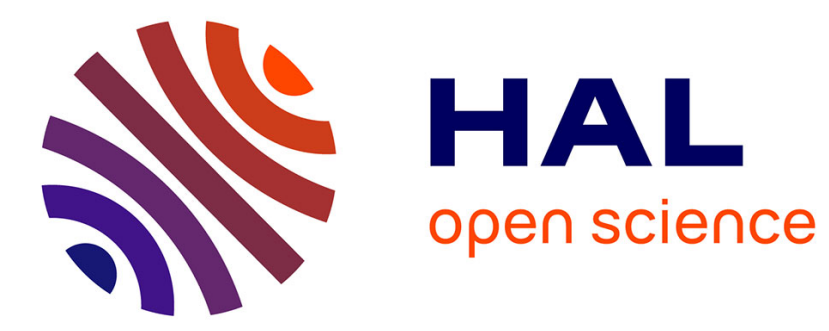

\title{
Applications of Positron Annihilation Spectroscopy
}

P. Asoka-Kumar, K. Lynn

\section{To cite this version:}

P. Asoka-Kumar, K. Lynn. Applications of Positron Annihilation Spectroscopy. Journal de Physique IV Proceedings, 1995, 05 (C1), pp.C1-15-C1-25. 10.1051/jp4:1995102 . jpa-00253538

\section{HAL Id: jpa-00253538 https://hal.science/jpa-00253538}

Submitted on 1 Jan 1995

HAL is a multi-disciplinary open access archive for the deposit and dissemination of scientific research documents, whether they are published or not. The documents may come from teaching and research institutions in France or abroad, or from public or private research centers.
L'archive ouverte pluridisciplinaire HAL, est destinée au dépôt et à la diffusion de documents scientifiques de niveau recherche, publiés ou non, émanant des établissements d'enseignement et de recherche français ou étrangers, des laboratoires publics ou privés. 


\title{
Applications of Positron Annihilation Spectroscopy
}

\author{
P. Asoka-Kumar and K.G. Lynn \\ Brookhaven National Laboratory, Upton, New York 11973, U.S.A.
}

We describe the application of Positron Annihilation Spectroscopy (PAS) to some selected technologically important systems. The method involves a nondestructive probe to detect low levels of open-volume defects. The discussion shows the application of PAS to a wide range of advanced material systems.

\section{Introduction}

The nature of defects and its control have been a subject of continued interest to the material research community. With the development of newer and better techniques for the growth and processing of materials, a corresponding refinement of their characterization technique is essential. With many advanced systems, a single characterization method is often inadequate. Therefore, the material research community has relied on a large variety of techniques to control and optimize their processing steps. In this context, Positron Annihilation Spectroscopy (PAS) is emerging as a unique probe for low levels of open-volume-type defects. The salient features of the technique are: Nondestructiveness, depth-sensitivity, and ease of use. Because of these features, the method can be potentially developed as a non-contact, on-line probe at critical stages of some types of manufacturing line.

Here we describe recent successes of the PAS technique in examining different classes of materials. This includes: Thin films of $\mathrm{Si}$ grown by molecular beam epitaxy, buried interfaces of $\mathrm{SiO}_{2}-\mathrm{Si}$ system, thermal voiding and electromigration in $\mathrm{Al}(\mathrm{Cu})$ interconnects, and correlation of polycrystalline $\mathrm{CuInSe}_{2}$ cell efficiency with homojunction depth. Before describing these results a brief introduction to the PAS technique is also provided.

\section{Background}

Positron annihilation spectroscopy, as the name suggests, is the spectroscopy of photons emerging from the annihilation of positrons with electrons. The depth-resolved PAS method is based on: (1) the availability of beams [1-6] of positrons that can be used to probe various controlled depths (in the few $\mu \mathrm{m}$ range)[7] of a material; (2) the propensity of positrons to seek out the low-density region of a solid such as voids and vacancies [8,9]; and (3) the annihilation of positrons and electrons into $\gamma$-rays that carry information about the low-ion-density regions and escape the test material without significant attenuation[1].

When positrons are implanted into a material, they are thermalized rapidly through inelastic collisions. The thermalized positrons diffuse and annihilate with electrons, either from a freely diffusing state or from a trapped state (at a defect site), predominantly producing two gamma rays. Because of the 
center of mass motion of the annihilating positron-electron system, the gamma rays will be Doppler shifted from the center energy of $511 \mathrm{keV}$. Because the positrons are thermalized, the Doppler shift will be dominated by the momentum of the electrons participating in the annihilation, and can be used to study the properties of the electron momentum distribution. In an experiment where energies of the several annihilation photons (both up shifted and down shifted) are recorded, the Doppler shift of the individual $\gamma$-ray line will contribute to an overall broadening of the annihilation photopeak; this is often called Doppler broadening[5].

The Doppler broadened spectrum can be characterized by using some part of the momentum spectra: One such parameter is an S parameter, defined as the ratio of counts (i.e., area) in a central region of the photopeak to the total counts (area) in the peak. The $S$ parameter has a simple relationship to the Doppler broadening: For example, if the annihilation peak is narrow, which results when positrons annihilate predominantly with slow-moving electrons, the $\mathrm{S}$ parameter is large, and vice versa. Thus, annihilations with the valence electrons are reflected in the $S$ parameter. Similarly the wing region of the spectrum (defined as $\mathrm{W}$ parameter) can be used to examine the contributions from core electrons in Doppler broadening.

The use of simple parameters such as $\mathrm{S}$ and $\mathrm{W}$ yields extensive information about the low-density region (open-volume-defects) of a solid material. The absolute values of $\mathrm{S}$ and $\mathrm{W}$ parameters have little physical relevance, since they are essentially decided by the position of the windows chosen in their definition. It is the relative change in these parameters that carries information about the annihilation sites. Therefore $\mathrm{S}$ and $\mathrm{W}$ parameters are usually normalized to a reference value corresponding to the defect-free (as seen by positrons) value of the material under investigation. The normalized value can then be compared between different samples and experimental arrangements. Because Doppler broadening parameters can be measured and interpreted very rapidly, they are used extensively in defect-related studies.

The $S$ parameter is usually measured as a function of positron beam energy (E), resulting in S-E data. The energy can be converted to an approximate mean depth by using

$$
z[\mathrm{~nm}]=\frac{A E[\mathrm{keV}]^{n}}{\rho\left[g m / \mathrm{cm}{ }^{3}\right]},
$$

where $\mathrm{A}$ and $\mathrm{n}$ are material dependent constants and $\rho$ is the density of the test material. The S-E data can be analyzed using a diffusion-annihilation equation[5] using computer codes like VEPFIT[10]. The analysis yields parameters such as: S-parameter of a particular region of the test system, positron diffusion length, internal electric field, and boundary between different regions. The positron diffusion length can easily be correlated to the defect concentration[5].

\section{Applications}

\subsection{Defects in Si grown by low-temperature molecular beam epitaxy}

The growth and doping of thin films of Si by molecular beam epitaxy (MBE) allow engineering of novel device structures. However, the conventional MBE growth at elevated temperatures $\left(\geq 450^{\circ} \mathrm{C}\right)$ places significant restriction on the composition and doping profiles that can be achieved. Recently, it has been shown that the MBE of Si can be sustained even at low temperatures[11,12], thus solving the "Si doping problem" (i.e., at conventional growth temperatures dopant segregation is severe and incorporation is below unity). For low-temperature MBE (LT-MBE) of Si, the epitaxial growth proceeds to a limiting thickness $h_{e p i}$, beyond which the crystalline growth turns to an amorphous growth. The memory of a limiting epitaxial thickness can be erased by rapid thermal annealing (RTA), in which the 
growing film receives a short $(150 \mathrm{sec})$ exposure to an elevated temperature $\left(\sim 500^{\circ} \mathrm{C}\right)$. The typical growth temperature used in the present study is about $220^{\circ} \mathrm{C}$.

The very low temperature employed in LT-MBE raises the question of the quality of the film. Conventional techniques, such as electron microscopy and ion scattering can only rule out extended defects and places a high limit on point-defect concentrations. PAS, on the other hand can detect dilute quantities $\left(-5 \times 10^{17} \mathrm{~cm}^{-3}\right)$ of vacancylike defects in crystalline materials. Detailed PAS studies of overlayers grown under various deposition conditions showed the unique capabilities of the positron probe in solving defect-related problems in these classes of advanced materials $[13,14,15,16]$.

Figure 1 shows the $\mathrm{S}$ parameter measurements from LTMBE samples grown in a custom MBE chamber to a thickness of 200 $\mathrm{nm}$. The details of the growth process can be found in ref. 14. One of the samples received an RTA anneal at a peak temperature of $T_{R T A}=600^{\circ} \mathrm{C}$, while the other received an RTA anneal at $450^{\circ} \mathrm{C}$. The figure also includes measurements from a control Si wafer. The conventional characterization techniques, such as ion scattering and electron microscopy show that the films grown under these conditions are indistinguishable from the control $\mathrm{Si}$ wafer[11,12,14]. However, positron measurements show clear differences between the samples. The sample grown at $600{ }^{\circ} \mathrm{C}$ is identical to control $\mathrm{Si}$, thus setting an upper limit

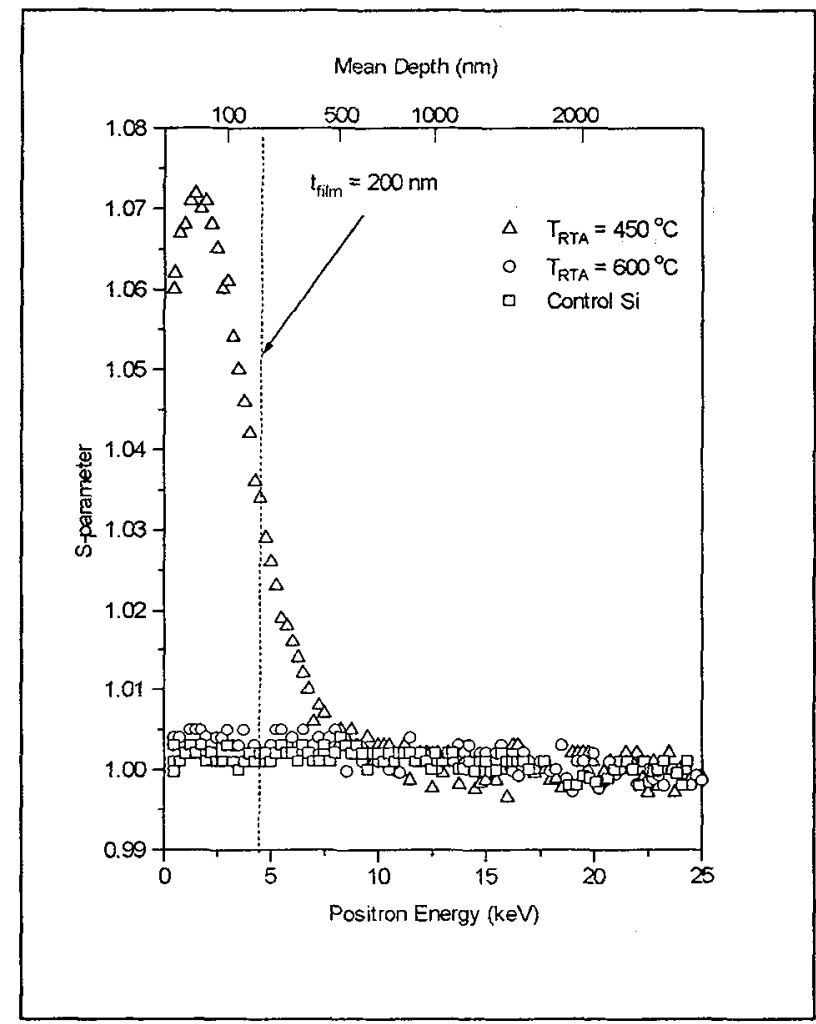

Figure 1 Comparison of Doppler-broadening

measurements from LT-MBE films grown at $220^{\circ} \mathrm{C}$ with different RTA temperatures and a control Si sample. of $5 \times 10^{15} \mathrm{~cm}^{-3}$ for vacancy-like defects[14]. A sharp increase in defect signal is observed when RTA temperature is lowered to $450{ }^{\circ} \mathrm{C}$. A VEPFIT analysis of the S-E data gave a defect concentration of $\sim 10^{18} \mathrm{~cm}^{-3}$. A nuclear reaction analysis of the hydrogen content in the film showed that hydrogen incorporation during MBE growth may play a significant role in the breakdown of epitaxy in films grown at $T_{R T A}=450^{\circ} \mathrm{C}[16]$.

The difference seen with PAS between samples processed at $\Upsilon_{\mathrm{RTA}}$ of $600{ }^{\circ} \mathrm{C}$ and $450{ }^{\circ} \mathrm{C}$ correlated well with a corresponding degradation in electrical characteristics of pn junctions made from these materials[14]. The current-voltage characteristics of two batches of samples showed that the diodes made from films with $\mathrm{T}_{\mathrm{RTA}}=600^{\circ} \mathrm{C}$ have significantly smaller reverse-bias leakage current than those with $\mathrm{T}_{\mathrm{RTA}}=450^{\circ} \mathrm{C}$, showing that there are defects in the latter, consistent with the PAS study. Thus PAS is a sensitive and useful probe to monitor defect concentrations at a level lower than all other structural techniques, but of direct consequence to the electronic properties of advanced device structures. 
A more detailed depth-profiling of defects using PAS can be achieved by removing thin layers (in steps of $10 \mathrm{~nm}$ ) of films from top by aqueous KOH etching[15]. The S-E data were collected after each etching step and the process is repeated until the defect signal is below the detection limit. A VEPFIT analysis of the data provided a more detailed defect-distribution in the MBE film. The PAS measurements with well-controlled chemical etching gave a depth resolution of $10 \mathrm{~nm}$, a significant improvement in the inherent depth-resolving limit of the PAS technique.

\subsection{PAS of $\mathrm{SiO}_{2}$-Si interface}

$\mathrm{SiO}_{2}-\mathrm{Si}$ system forms the backbone of several very large scale integration (VLSI) systems. Although there are extensive studies on the properties of $\mathrm{SiO}_{2}-\mathrm{Si}$ system, many fundamental properties are not known precisely. Positron annihilation spectroscopy of the oxide and the interface has shown several interesting features[17-30]. Figure 2 shows typical $\mathrm{S}-\mathrm{E}$ data from a $\mathrm{SiO}_{2}-\mathrm{Si}$ system, having a $110 \mathrm{~nm}$ thick oxide layer grown by a dry thermal process in an ambient containing no $\mathrm{HCl}$. The system was not subjected to a post-oxidation anneal. The S-E data shows that distinct annihilation signals are produced from the surface, oxide layer, interface, and bulk Si[17]. The solid line through the data points is from VEPFIT analysis. A distinct signal from the interface opens the possibility of probing the interface properties as a function of processing parameters and external parameters, such as electric field and ionizing radiations.

Trap centers at the $\mathrm{SiO}_{2}-\mathrm{Si}$ interface have long been recognized to be an impediment to an optimum performance of a metal-oxide-semiconductor device. The trap centers are produced mostly by broken $\mathrm{Si}$ dangling bonds at the interface. Therefore, reducing their densities to acceptable values $\left(\sim 10^{10} \mathrm{~cm}^{-2} \mathrm{eV}^{-1}\right)$ has been a subject of intense studies in the past. The reduction of these trap centers is achieved by annealing the system at low temperatures $\left(300-400^{\circ} \mathrm{C}\right)$ in an ambient containing trace amounts of hydrogen or water, either after oxidation or after metallization[31]. The chemical reaction responsible for the observed reduction is believed to be the passivation of $\mathrm{Si}$ dangling bonds by hydrogen. Therefore, the kinetics of the chemical reaction between interface trap centers and

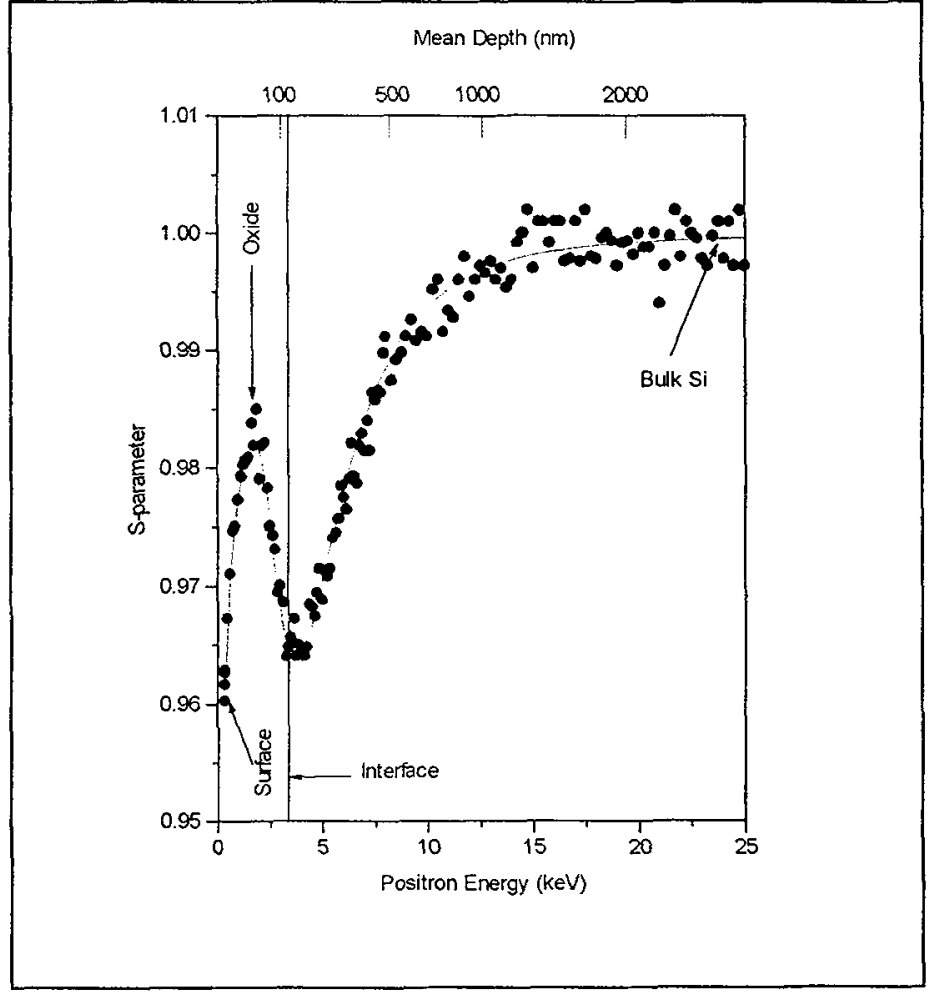

Figure 2 The Doppler broadening parameter (S) as a function of energy of a $\mathrm{SiO}_{2}-\mathrm{Si}$ system. The solid curve through the data points is a best fit using VEPFIT. hydrogen has to be properly understood to optimize the processing steps. Recent studies[30] using PAS derived the activation energy for the thermal dissociation of hydrogen passivated trap centers. 
The interface S-parameter is sensitive to the passivation state of the interface traps[20]. Positrons are readily trapped at the interface trap centers and annihilate with characteristic S-values, thus accounting for the low interface $\mathrm{S}$ value observed in Fig. 2. The model proposed by Au et al.[25] requires positrons to annihilate with an electron in the nearby oxygen atom, because a Si dangling orbital alone cannot produce a low $\mathrm{S}$ value as revealed by a number of PAS studies of ion-implanted $\operatorname{Si}[32]$.

Figure 3 shows the behavior of the interface $S$ parameter as function of isochronal annealing temperature carried out for 30 min, each in steps of $50{ }^{\circ} \mathrm{C}$. Before the start of the annealing series, the sample was annealed in an ambient containing hydrogen at $10^{-3}$ Torr for 30 minutes at $400{ }^{\circ} \mathrm{C}$ This pretreatment of the sample produces an interface with maximum number of hydrogen passivated dangling bond sites. Upon subsequent annealing, as shown in Fig. 3, the interface $S$-parameter shows an increase that is dependent upon the amount of thermally broken $\mathrm{Si}-\mathrm{H}$ bonds. The increase in S-parameter is completely reversible, i.e., the starting S-value can be regained by annealing the sample again in an ambient containing hydrogen[27], thus

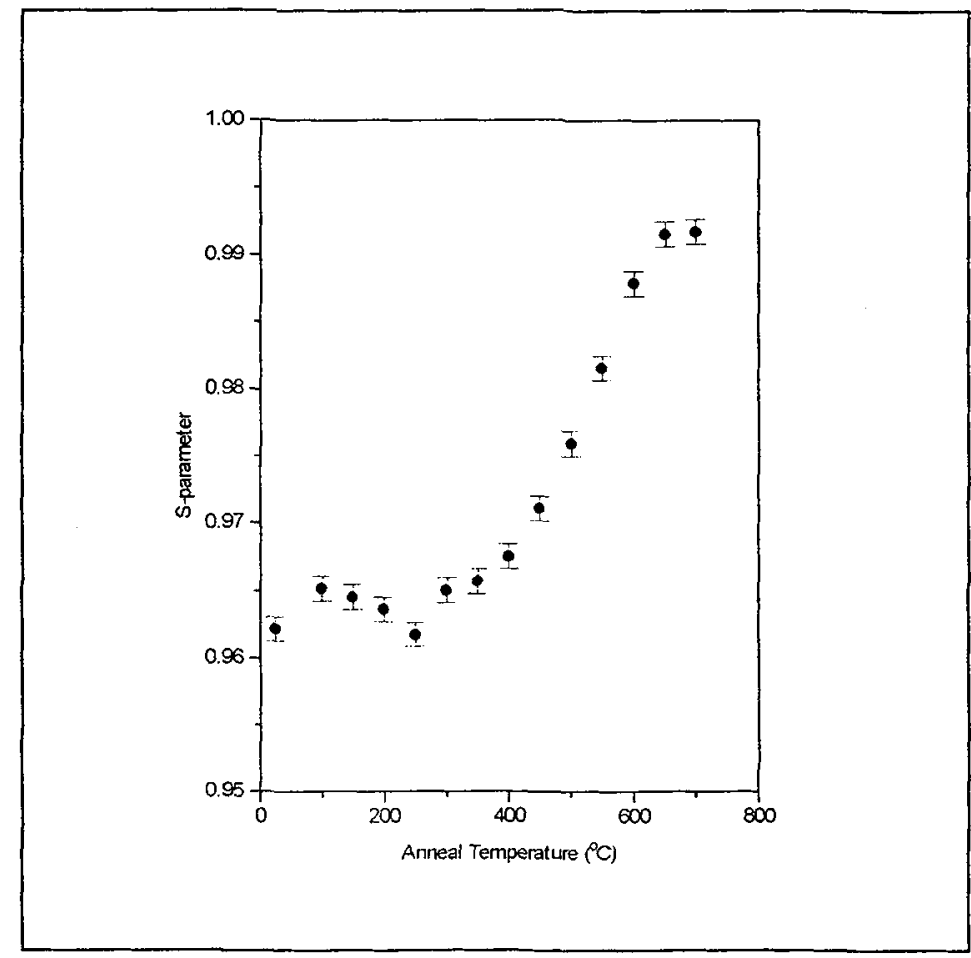

Figure 3 The interface $\mathrm{S}$ parameter of an $\mathrm{SiO}_{2}-\mathrm{Si}$ system as a function of isochronal anneal temperature. confirming that the thermal breakup of $\mathrm{Si}-\mathrm{H}$ bonds is responsible for the increase observed in Fig. 3 .

Assuming a first order process for the thermal break up of Si-H bonds, a model fitted to the data can be used to derive the activation energy for Si-H bond breaking. Assuming a value of $10^{13} \mathrm{~s}^{-1}$ for the attempt frequency, the activation energy for the thermal breakup was derived as $2.60 \pm 0.06 \mathrm{eV}$. A model fit to the S-E data using VEPFIT showed a charge buildup at the interface because of the Si-H bond breaking. Assuming the annealing modifies the concentration of trap centers with a single charge, the increase in internal electric field can be explained by the creation of $-0.5 \times 10^{9}$ trap centers $/ \mathrm{cm}^{-2}$. These measurements show the sensitivity of the PAS technique to the changing passivation state of the interface trap centers and charge buildup at buried interfaces.

\subsection{Thermal voiding and electromigration induced vacancies in thin $\mathrm{Al}(\mathrm{Cu})$ lines}

The high packing densities of devices in modern VLSI (with as many as $10^{8}$ transistors on a single chip) and expected further increase in the ultra-scaled systems, have raised the reliability issue of metallic interconnects. Failure of aluminum and aluminum-alloy interconnects by void formation from 
thermal stress and electromigration has been an area of immense importance to a device manufacturer. The mean-time-to-failure tests are often made by noting changes in the electrical properties (resistance, $1 / \mathrm{f}$ noise, etc.) and microscopic tests are used to observe structural damages. However, these tests either require a sampling of large numbers of test systems, or they are performed after significant changes have taken place in the interconnect lines. On the other hand by being a microscopic probe for dilute quantities of vacancy-like defects, PAS can be used for in situ monitoring of the early stages of these failure modes[33,34].

The formation of voids in $\mathrm{SiO}_{2}$-passivated $\mathrm{Al}(\mathrm{Cu})$ lines was observed under thermal stress by measuring positronium (Ps) formation[33]. Because positronium (a bound state of electron and positron) is readily formed in large voids, and because the annihilation spectrum in the presence of positronium formation is markedly different, PAS offers a sensitive probe for detecting void formation. After aging the system at an elevated temperature for less than an hour, a large increase in the Ps signal was observed as shown in Fig. 4. The rapid increase of the Ps signal (by $~ 1.5 \%$ ) under the heat treatment argues against any significant vacancy-induced void growth. Continued heating at elevated temperatures for $>$ $100 \mathrm{~h}$ did not increase the Ps signal. A sample annealed in $\mathrm{N}_{2}$ ambient also failed to show the Ps signal. These combined results suggest that brief heating in a vacuum is driving gas atoms (introduced at the processing stage) out of voids, and is enhancing the Ps formation. More studies are required to establish if these voids are the same ones that contribute to the failure mechanism.

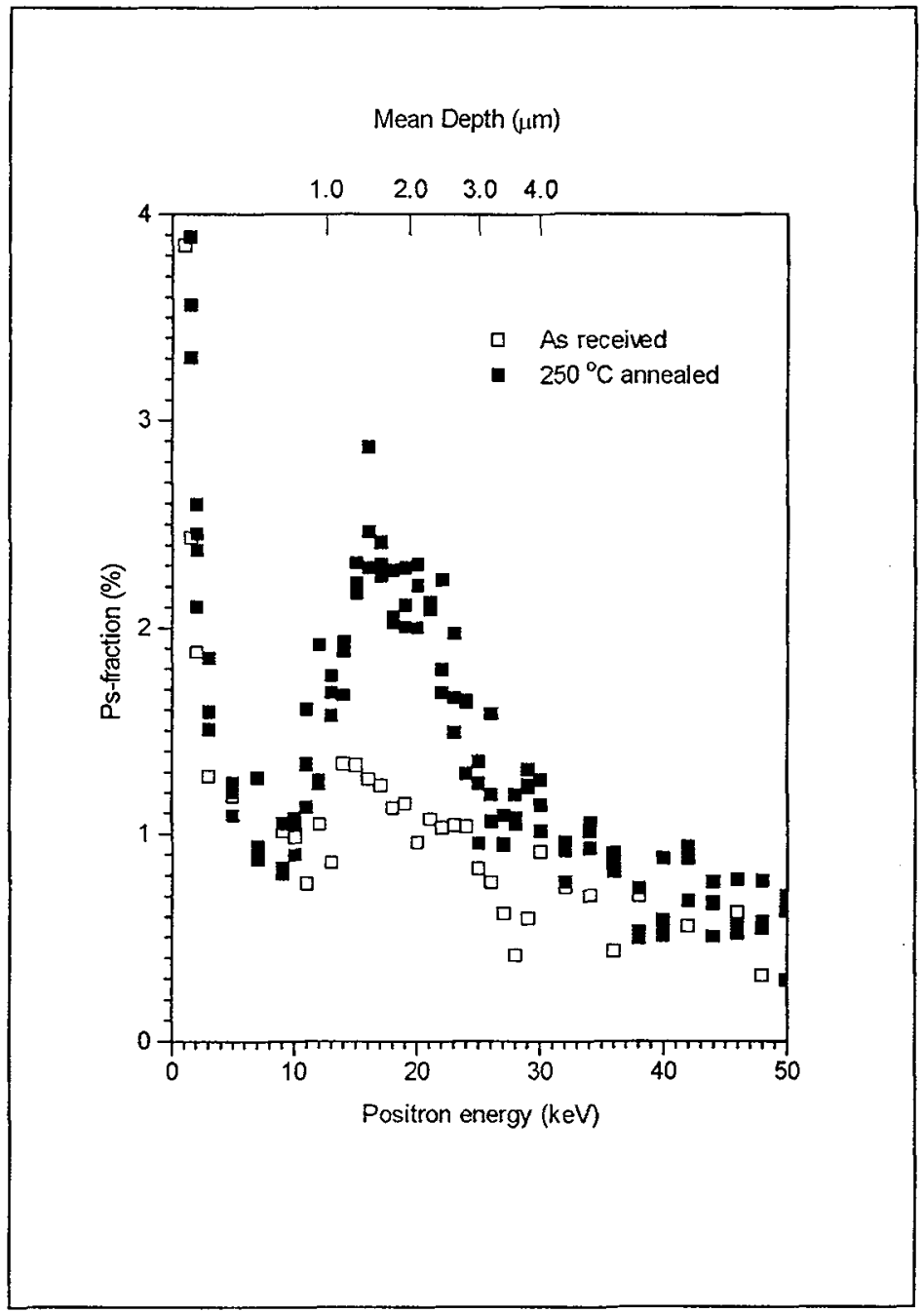

Figure 4 The $\mathrm{Ps}$-fraction from a system containing $\mathrm{SiO}_{2}$-passivaed $\mathrm{Al}(\mathrm{Cu})$ lines. The line are $1 \mu \mathrm{m} \times 1 \mu \mathrm{m}$ and are spaced $l \mu \mathrm{m}$ apart.

PAS can also be used to study the generation of vacancies as a result of electromigration in thin interconnect lines for integrated circuits. Despite the reliability problems posed by the electromigration failures, the fundamental process responsible for electromigration is not well understood. The mass transport along the conductor lines will be decided to a large extent by the kinetics of vacancy 
production, annihilation, and migration. Addition of solute atoms such as $\mathrm{Cu}$ improves the mean-time-to-failure rate of Al interconnects. Therefore, the interaction of solute atoms with vacancies also has to be properly understood. PAS has been used to study vacancy formation, vacancy agglomeration, and vacancy-impurity complexes in bulk $\mathrm{Al}$ in the past [35,36]. The interaction of vacancies and solute atoms in aluminum has been studied by thermal equilibrium measurements of Doppler broadening[36]. Similar measurements in thin Al lines with different solute atoms of differing concentration can yield valuable information about the role of solute atoms in inhibiting the electromigration of atoms.

Figure 5 shows the S-E data from a system containing $1 \mu \mathrm{m}$ lines spaced at $1 \mu \mathrm{m}$ on a $\mathrm{SiO}_{2}-\mathrm{Si}$ system. The aluminum lines contained $0.5 \% \mathrm{Cu}$ by weight. Addition of $\mathrm{Cu}$ is known to increase the mean-time-to-failure. Because the positron beam is much bigger than the line width and the lines cover only half the surface area, the S-parameter

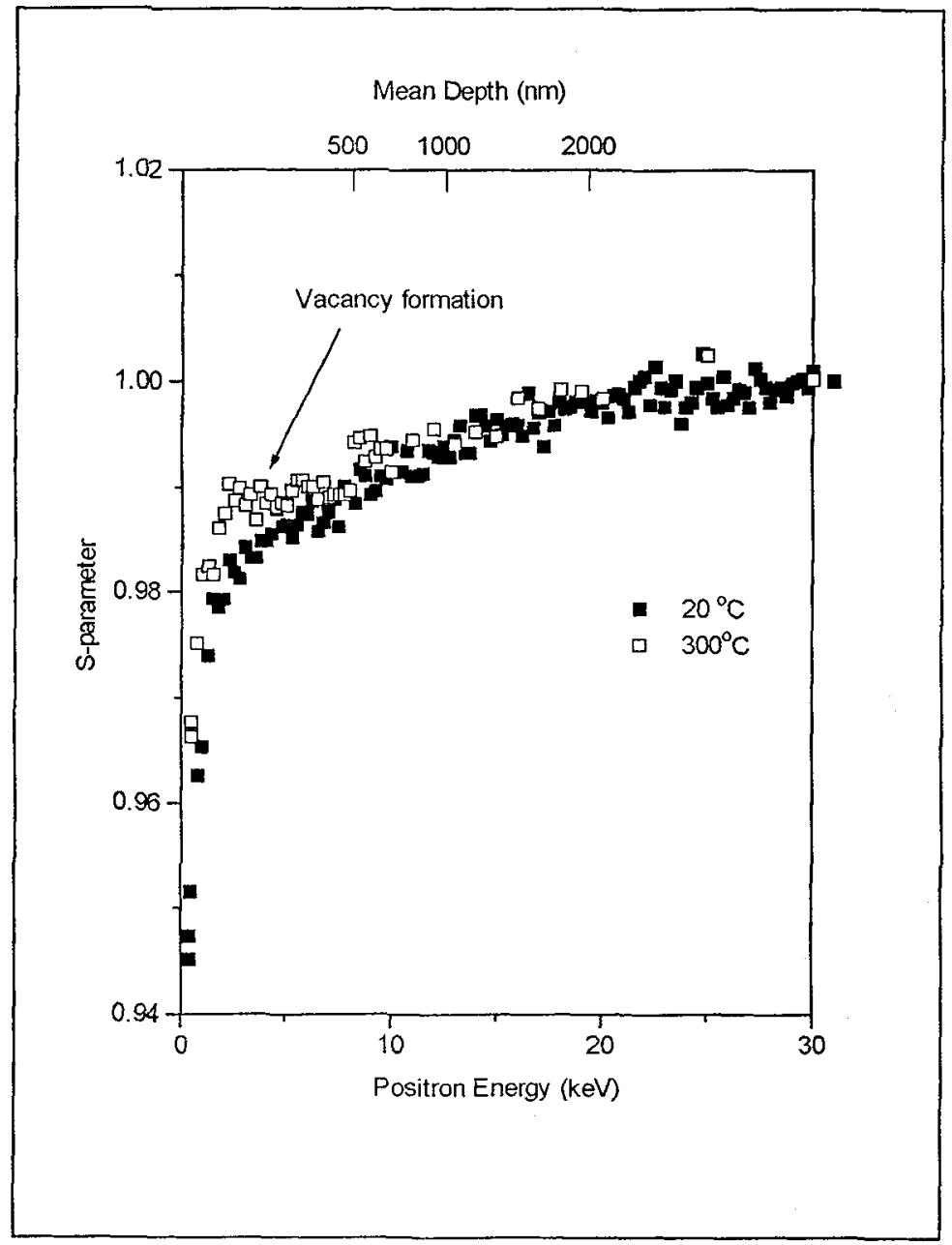

Figure 5 The $\mathrm{S}-\mathrm{E}$ data from a system containing $\mathrm{Al}(\mathrm{Cu})$ line on a $\mathrm{SiO}_{2}-\mathrm{Si}$ system. The $300{ }^{\circ} \mathrm{C}$ measurements show thermal generation of vacancies. increase due to thermal generation of vacancies will be only half the size of increase in S reported in refs. 35 and 36 . These kinds of measurements can provide equilibrium vacancy concentration and vacancy-formation energy. The variation of vacancy concentration and formation energy with $\mathrm{Cu}$ addition[36] can be examined systematically to optimize the elecromigration resistance of these lines.

Figure 6 shows a system with $8 \times 10^{4} \mathrm{~A} / \mathrm{cm}^{2}$ current flowing through the lines. The temperature of the lines during current flow is monitored with a setup identical to the setup used for data collection in Fig. 5 and is similar to the thermal equilibrium measurements. Clearly, an increase in the S-parameter signal is evident in Fig. 6 . The result shows the dynamic formation of excess vacancies during current flow. When the line temperature is brought down to $\angle 100$ " $\mathrm{C}$, the S-parameter data were similar to the one observed without any current. Thus the excess vacancy formation (relative to the thermal generation) 
occurs only when the current is present and the line temperature is kept above $100{ }^{\circ} \mathrm{C}$. Similar studies with varying solute atom concentration can provide kinetics of the solute atoms in preventing the electromigration failure. A prolonged $S$ parameter measurement with current flow can be undertaken to see the dynamic evolution of voids, which would eventually lead to a line failure.

\subsection{Correlation of PAS with solar cell efficiency in $\mathrm{CuInSe}_{2}$}

Thin films of the ternary chalcopyrite semiconductor, copper indium diselenide (CIS), have been viewed as a promising absorber material in heterojunction solar cells[37]. Advances in thin film deposition techniques for CIS have produced devices with high active-area efficiencies[37]. The large scale manufacturing of devices based on these technologies require a proper understanding of the correlation of the device efficiency [38] with the CIS stoichiometry or defect concentrations. The structural deviations from the basic chalcopyrite structure can modify the efficiency drastically.

Recently, PAS has been used to correlate the CIS device efficiency to the structural imperfections in the deposited film [39]. Depending on the deposition parameters, structural defects can form in the basic lattice of CIS, for e.g., incorporation of excess In results in unoccupied Cu-sites. Also, $\mathrm{Cu}$ vacancies are known to occur at well-defined positions, leading to the term "ordered vacancy compound." More often, the defect-structure segregates at the surface of the deposited films, and can reduce the cell efficiency.

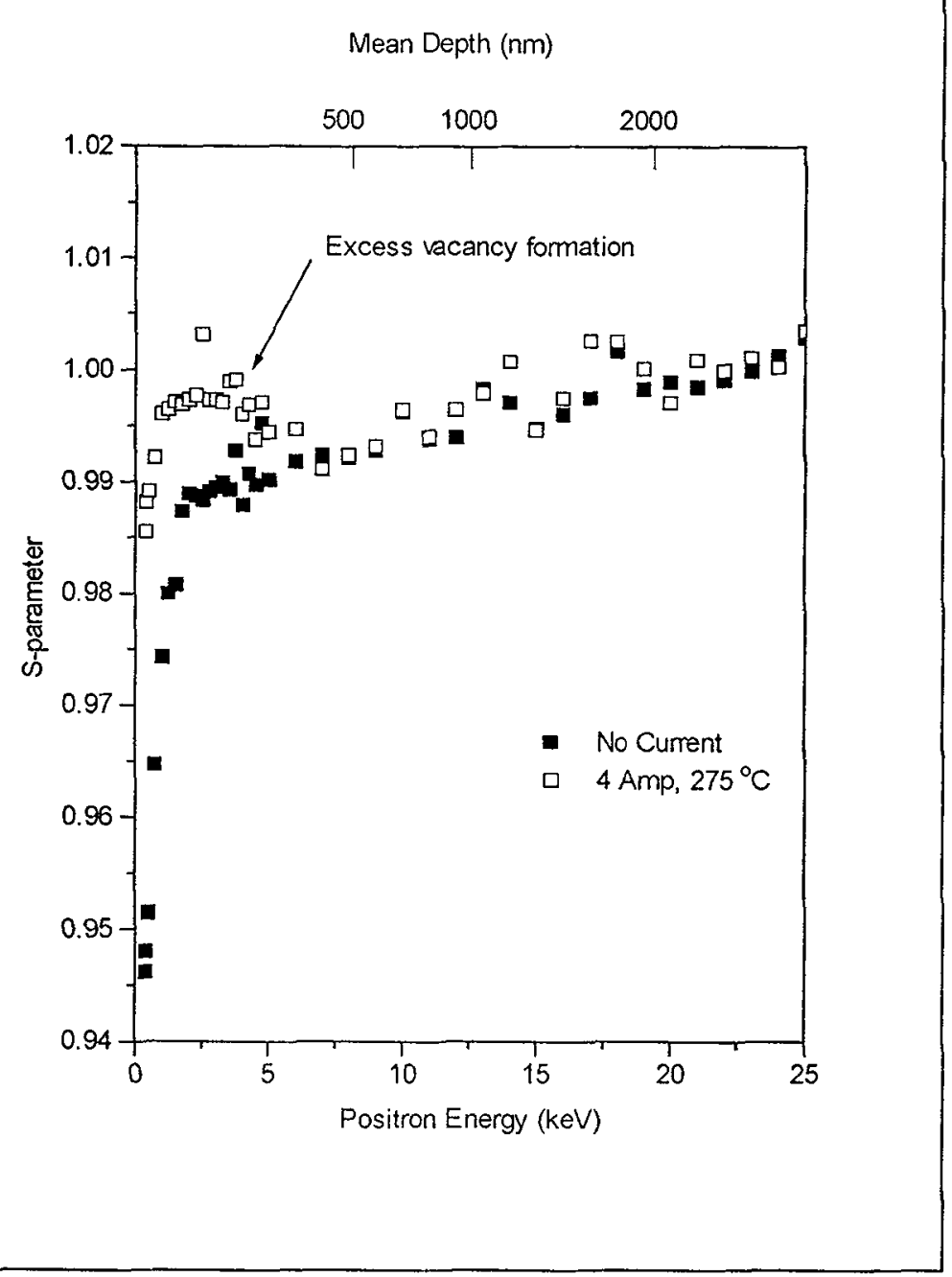

Figure 6 S-E measurements from a system containing $\mathrm{Al}(\mathrm{Cu})$ lines on $\mathrm{SiO}_{2}-\mathrm{Si}$ system. The current flow show excess vacancy formation compared to results in Fig. 5 . 
The p-type CIS films were fabricated by a physical vapor deposition process on Mo-coated soda lime glass substrates. Devices made from different areas of these films gave total area efficiencies of $13.2 \%$ and $11.3 \%$. Angleresolved and high resolution $X-r a y$ photoelectron spectroscopy yielded a surface composition of $\mathrm{Cu}: \mathrm{In}: \mathrm{Se}=$ 1:5:8 (or a two-phase mixture of $\mathrm{In}_{2} \mathrm{Se}_{3}$ and $\left.\mathrm{CuIn}_{3} \mathrm{Se}_{5}\right)$ and $\mathrm{a}$ single phase of $\mathrm{In}_{2} \mathrm{Se}_{3}$, respectively. For the device with $13.2 \%$ efficiency, the mixed phase is more probable because the $\mathrm{Cu}_{2} \mathrm{Se}-\mathrm{In}_{2} \mathrm{Se}_{3}$ phase diagram does not support a $\mathrm{CuIn}_{5} \mathrm{Se}_{8}$ phase.

Figure 7 shows the $S$ $E$ results from the device structure that yielded $13.2 \%$ and $11.3 \%$ efficiencies [38]. The data are normalized to the bulk glass substrate. For the film with lower efficiency, the S-parameter data suggests the presence of open-volume defects toward the surface. The film with $13.2 \%$ efficiency has a more uniform

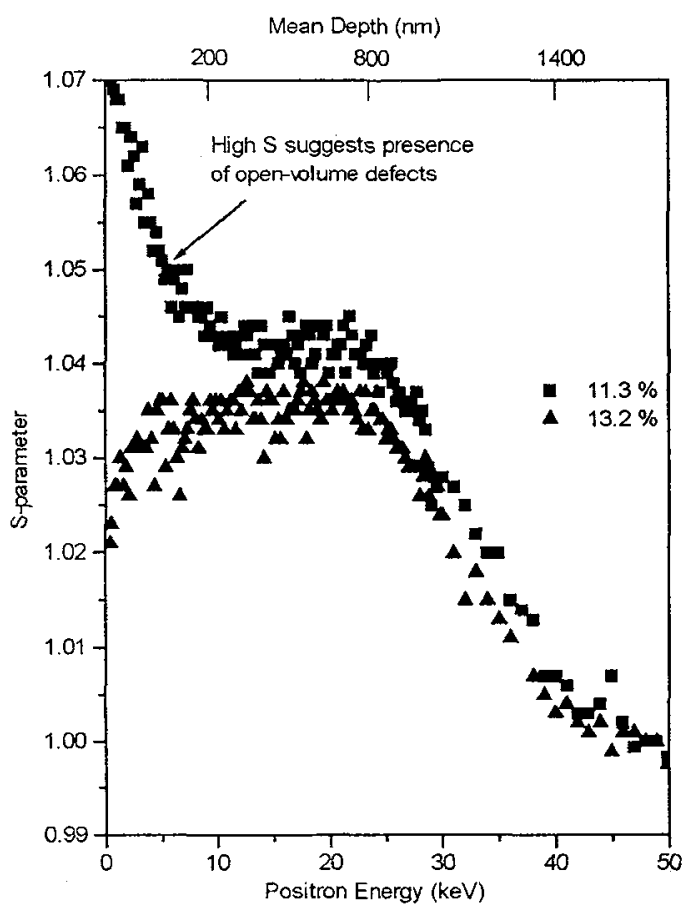

Figure 7 The S-E data from $\mathrm{CuInSe}_{2}$-films showing different solar cell efficiencies. A low efficiency correlates well with more defects near the surface.

composition. Thus, fewer defects in the $\mathrm{Cu}$-poor $\mathrm{n}$-type surface layer correlates with a better overall device performance.

\section{Conclusion}

Our discussion showed the use of positron annihilation spectroscopy as a characterization tool to reveal the nature, concentration, and spatial distribution of defects in a few selected advanced material systems. The technique is simple to use and provides rapid information about the open-volumedefect content with a sensitivity unparalleled by other techniques. In the future, with the development of more intense positron beams, the depth-resolved spectroscopy will be extended to other positron observables, such as lifetime and two-dimensional angular correlation. In principle, these measurements will provide a more sophisticated picture for the electron momentum distribution and open-volume content of a defect site.

\section{Acknowledgements}

We thank our collaborators for many fruitful discussions. The work was supported by U.S. Department of Energy under contract No. DE-ACO2-76CH000I6. 


\section{References}

[1] Positron Solid State Physics, Proceedings of the International School of Physics "Enrico Fermi," Course LXXXIII, Varena, 1981, edited by W. Brandt and A. Dupasquier (North Holland, Amsterdam, 1983).

[2] Slow Positrons in Surface Science, Proceedings of the International Workshop, Pajulathi, Finland, ed. by, A. Vehanen (Helsinki University of Technology Report No. 135, 1984).

[3] Proceedings of the MURR Slow Positron Beam Workshop, University of Missouri, Columbia, Missouri, ed. by, D.C. Reichel and W.B. Yelon (Unpublished 1985)

[4] Proceedings of the International Workshop on Slow Positron Beams for Solids and Surfaces, Norwich, England, ed. by, P.G. Coleman and A.B. Walker (Unpublished, 1986).

[5] P.J. Schultz and K.G. Lynn, Rev. Mod. Phys., 60, 701 (1988).

[6] Positron Beams for Solids and Surfaces, Proceedings of the Fourth International Workshop on SlowPositron Beam Techniques for Solids and Surfaces, edited by P.J. Schultz, G.R. Massoumi, and P.J. Simpson, (American Institute of Physics, New York, 1990).

[7] W. Trifthäuser and G. Kögel, Phys. Rev. Lett., 48, 1741 (1982).

[8] S. Berko and J.C. Erskine, Phys. Rev. Lett., 19, 307 (1967)

[9] I.K. MacKenzie, T.L. Khoo, A.B. McDonald, and B.T.A. McKee, Phys. Rev. Lett., 19, 946 (1967).

[10] A. van Veen, H. Schut, J. de Vries, R.A. Hakvoort, and M.R. Ypma, in reference [6].

[11] D.J. Eaglesham, H.-J. Gossmann, and M. Cerullo, Phys. Rev. Lett., 65, 1127 (1990).

[12] H.-J. Gossmann, E.F. Schubert, D.J. Eaglesham, and M. Cerullo, Appl. Phys. Lett., 57, 2440 (1990)

[13] H.-J. Gossmann, P. Asoka-Kumar, T.C. Leung, B. Nielsen, K.G. Lynn, F.C. Unterwald, and L.C. Feldman, Appl. Phys. Lett., 61, 540 (1992).

[14] P. Asoka-Kumar, H.-J. Gossmann, F.C. Unterwald, L.C. Feldman, T.C. Leung, H.L. Au, V. Talyanski, B. Nielsen, and K.G. Lynn, Phys. Rev. B 48, 5345 (1993).

[15] Cs. Szeles, P. Asoka-Kumar, K.G. Lynn, H.-J. Gossmann, F.C. Unterwald, and T. Boone, Unpublished (1994).

[16] P. Asoka-Kumar, S. Szpala, B. Nielsen, Cs. Szeles, K.G. Lynn, W.A. Lanford, C.A. Shepard, H.-J. Gossmann, Submitted (1994).

[17] B. Nielsen, K.G. Lynn, Yen-C Chen, and D.O. Welch, Appl. Phys. Lett,, 51, 1022 (1987).

[18] A. Uedono, S. Tanigawa, K. Suzuki, and K. Watanabe, Appl. Phys. Lett, 53, 473 (1988).

[19] B. Nielsen, K.G. Lynn, D.O. Welch, T.C. Leung, and G.W. Rubloff, Phys. Rev. B 401434 (1989)

[20] P. Asoka-Kumar, K.G. Lynn, T.C. Leung, B. Nielsen, G.W. Rubloff, and Z.A. Weinberg, Phys. Rev. B 44, 5885 (1991).

[21] P. Asoka-Kumar, K.G. Lynn, T.C. Leung, B. Nielsen, and X.Y. Wu, J. Appl. Phys., 69, 6603 (1991).

[22] Y. Kong, T.C. Leung, P. Asoka-Kumar, B. Nielsen, and K.G. Lynn, J. Appl. Phys., 70, 2874 (1991)

[23] T.C. Leung, Y. Kong, K.G. Lynn, B. Nielsen, Z.A. Weinberg, and G.W. Rubloff, Appl. Phys. Lett., 58, 86 (1991).

[24] T.C. Leung, P. Asoka-Kumar, B. Nielsen, and K.G. Lynn, J. Appl. Phys., 73, 168 (1993)

[25] H.L. Au, P. Asoka-Kumar, B. Nielsen, and K.G. Lynn, J. Appl. Phys., 73, 2972 (1993).

[26] M. Fujinami and N.B. Chilton, Appl. Phys. Lett., 62, 1131 (1993).

[27] R. Khatri, P. Asoka-Kumar, B. Nielsen, L.O. Roellig, and K.G. Lynn, Appl. Phys. Lett., 63, 385 (1993).

[28] A. Uedono, L. Wei , S. Tanigawa, R. Suzuki, H. Ohgaki, T. Mikado, and Y. Ohji, J. Appl. Phys., 74, 7251 (1993).

[29] A. Uedono, L. Wei, S. Tanigawa, R. Suzuki, H. Ohgaki, T. Mikado, and Y. Fujino, J. Appl. Phys., 75,216 (1994).

[30] R. Khatri, P. Asoka-Kumar, B. Nielsen, L.O. Roellig, and K.G. Lynn, Appl. Phys. Lett., 65, 330 (1994).

[31] See, for example, E.H. Nicollian and J.R. Brews, in MOS (Metal Oxide Semiconductor) Physics and Technology (Wiley, New York, 1982), p 782-786, and references therein 
[32] See, for example, B. Nielsen, O.W. Holland, T.C. Leung, and K.G. Lynn, J. Appl. Phys., 74, 1636 (1993).

[33] P.J. Simpson, M.T. Umlor, K.G. Lynn, K.P. Rodbell, Appl. Phys. Lett., 65, 52 (1994).

[34] P. Asoka-Kumar, K. O'Brien, K.G. Lynn, P.J. Simpson, and K.P. Rodbell, Unpublished (1994).

[35] K.G. Lynn, J.E. Dickman, W.L. Brown, M.F. Robbins, E. Bonderup, Phys. Rev. B 20, 3566 (1979).

[36] S. Tanigawa, K. Ito, Y. Otsu, K. Shima, in Positron Annihilation, Ed. by P.G. Coleman, S.C. Sharma, and L.M. Diana, (North-Holland Publishing Co., 1982) p 503.

[37] See, for example, A. Rockett, F. Abou-Elfotouh, D. Albin, M. Bode, J. Ermer, R. Klenk, T. Lommasson, T.W.F. Russell, R.D. Tomlinson, J. Tuttle, L. Stolt, T. Walter, and T.M. Peterson, Thin Solid Films, 237, 1 (1994), and references therein.

[38] Solar cell efficiency is defined as the ration of the maximum power output to the incident power. [39] A.J. Nelson, A.M. Gabor, M.A. Contreras, J.R. Tuttle, R. Noufi, P.E. Sobol, P. Asoka-Kumar, and K.G. Lynn, Submitted to J. Appl. Phys., (1994). 